\title{
'Sumo' rats set researchers on hunt for obesity genes
}

The world's fattest rats are the focus of a new joint project for scientists from India and the US. The researchers hope to identify and clone the genes responsible for the 'sumo' rats that weigh in at about 1.4 kilograms (3.1 pounds), about four times the standard weight for a rat.

"If, as we believe, this is a new obesity gene, it could have major implications," says Nappan Veettil Giridharan, deputy director of India's National Institute of Nutrition (NIN) in Hyderabad. The NIN maintains a colony of about 400 sumo rats in their twenty-first generation. Giridharan says all evidence indicates that the genes may differ from all obese rat models currently available.

Like other rodent models, the sumo rats serve as good paradigms for human disorders such as diabetes and infertility. But unlike the other models, these rats also develop cataracts and tumors, and their infertility is fully reversible with simple measures such as diet restriction. The rats also have kinky tails, not seen in any other obese models.

From day 35 on, the rats rapidly gain weight and their body shape gradually

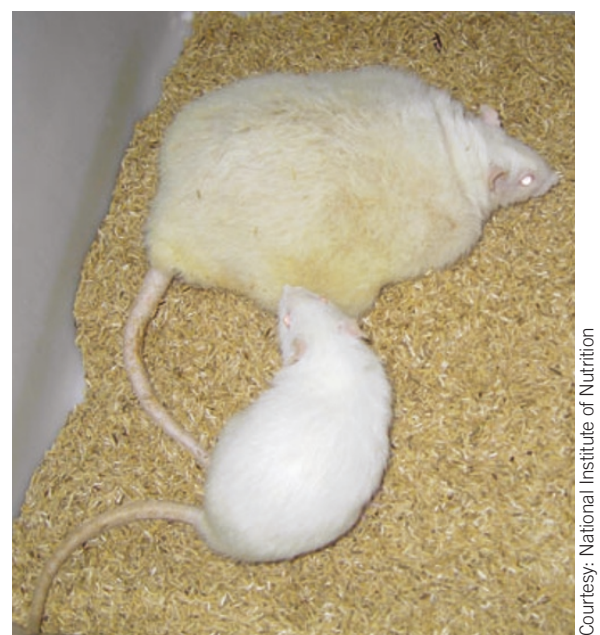

Fat rats at an Indian research institute may carry undiscovered obesity genes.

becomes rotund. Too fat to move, they lie supine with their heads close to the food pellets. They also show signs of rapid aging and die in about 18 months, compared with the normal three years, Giridharan says.

To map the mutation, Giridharan and his colleagues plan to cross the Indian rat with unrelated strains such as the Brown Norway and Fischer-344 strains. Genetic analysis on the resulting progeny will then help localize the mutation and ultimately clone it. DNA analysis will be carried out by the US collaborators, led by Jeffrey Friedman, at Rockefeller University in New York.

In 1994, Friedman and his colleagues cloned the obese gene and, in 1995, identified its product, leptin. Friedman showed that overweight mice with defective $o b$ genes-and who cannot make leptinrespond to injections of leptin by losing up to $30 \%$ of their body weight in two weeks.

The $\$ 500,000$ cost of the project is to be shared by the US National Institutes of Health and the Indian Council of Medical Research (ICMR).

"We are ready to start the project right away and hopefully clone the gene in two years," says Friedman. The ICMR is planning another large study to use the NIN rat to screen for potential obesity and diabetes drugs.

K. S. Jayaraman, Hyderabad

\section{Scientists irked by ethicists' alternatives for embryo research}

Stem cell scientists have a message for those who propose ethically friendly methods to alter human embryos: come on down and give it a shot.

"The ethicists seem to imagine that they can sit around a table and dream up these experiments," says Doug Melton, co-director of the Harvard Stem Cell Institute. “They don't seem to be cognizant of the enormous effort involved in proving even a small effect."

In December, William Hurlbut, a Stanford University ethicist and a member of the President's Council on Bioethics, generated a buzz when he suggested genetically or chemically altering human embryos so they cannot develop beyond the blastocyst stage. By doing so, Hurlbut said, scientists could pursue research without violating federal rules on embryonic stem cell research.

Hurlbut told the council that a process called 'altered nuclear transfer' may be able to generate functional cells from a blastocyte that cannot form a trophectoderm, the outer layer of cells that eventually forms the placenta. He suggested that scientists might be able to do this by deleting or blocking the action of the $C d x 2$ gene from the somatic cell nucleus before transfer and reinstalling it into the resulting embryonic stem cells.

Animal studies indicate that without $C d x 2$, a blastocyte can form an inner mass but cannot grow. Since the genetically altered embryo has no potential for life, Hurlbut notes, the process might mollify those who believe life begins at conception.

Melton says that it is not known whether $C d x 2$-deficient embryos die at the same stage as mice, and whether they could be used to produce stem cells. Research on these ideas would only divert energy and funding from more promising avenues, he says, and still might not satisfy opponents of stem cell research. "I am completely open to alternative approaches," Melton says. "I just think this one is flawed."

Proponents of Hurlbut's idea may be underestimating the potential scientific obstacles, but the idea is worth a try, says Irving Weissman, director of the Cancer and Stem Cell Institute at Stanford Univeristy in California. The preliminary research is not complicated or costly, he adds, but it may yield nothing.

"I say go ahead and do the experiments, compete for funds," he says. "But don't think that you can use this politically to slow down even for a minute the kind of research we are going to do in California, Korea, Japan, Israel and elsewhere.”

Meanwhile, Hurlbut and Burnham Institute's Evan Snyder plan to seek funds from California's new stem cell research fund (See News, page 107). Snyder says their research will also explore targets other than $C d x 2$.

"We've just put out feet on the Plymouth Rock, we have a whole continent to explore," Hurlbut says. "Why are we pretending we're prophets, why not just go out and see what's there?"

Tinker Ready, Boston

For more news and analysis go to news@nature.com www.nature.com/news 